PREPARED FOR THE U.S. DEPARTMENT OF ENERGY, UNDER CONTRACT DE-AC02-76CH03073

PPPL-3605

PPPL-3605

UC-70

On Plasma Rotation Induced

by Traveling Fast Alfvén Waves

by

F.W. Perkins, R.B. White, and V.S. Chan

August 2001

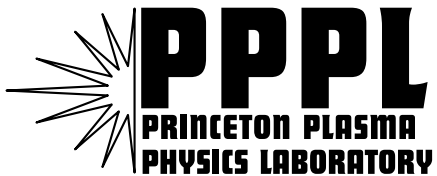

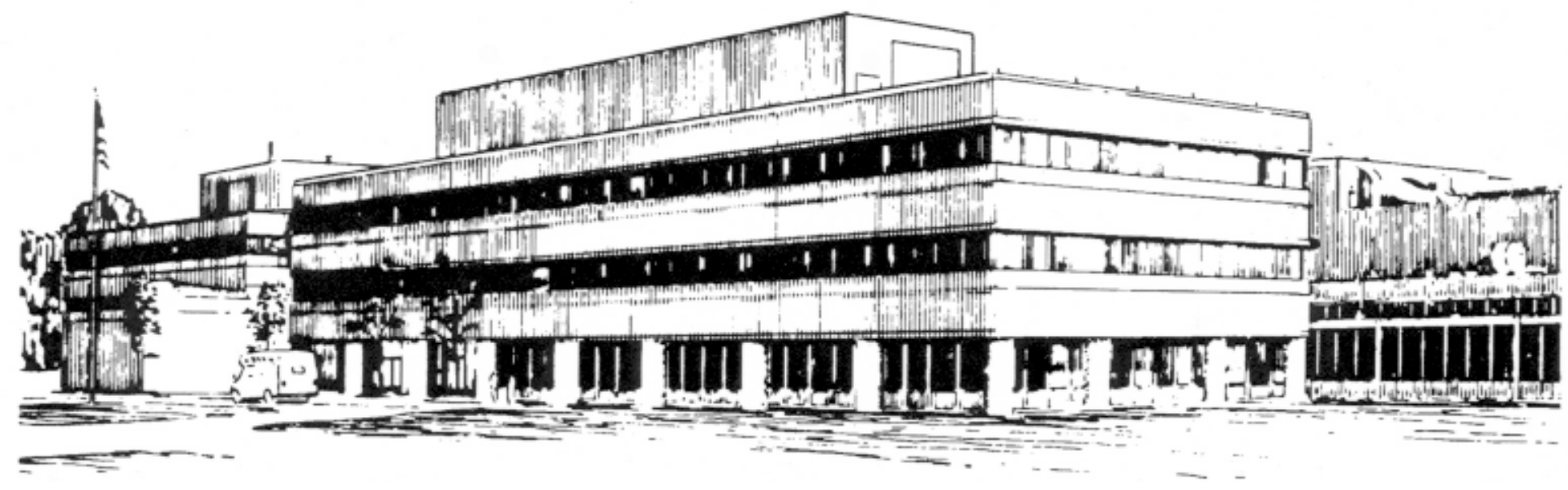

PRINCETON PLASMA PHYSICS LABORATORY PRINCETON UNIVERSITY, PRINCETON, NEW JERSEY 


\section{PPPL Reports Disclaimer}

This report was prepared as an account of work sponsored by an agency of the United States Government. Neither the United States Government nor any agency thereof, nor any of their employees, makes any warranty, express or implied, or assumes any legal liability or responsibility for the accuracy, completeness, or usefulness of any information, apparatus, product, or process disclosed, or represents that its use would not infringe privately owned rights. Reference herein to any specific commercial product, process, or service by trade name, trademark, manufacturer, or otherwise, does not necessarily constitute or imply its endorsement, recommendation, or favoring by the United States Government or any agency thereof. The views and opinions of authors expressed herein do not necessarily state or reflect those of the United States Government or any agency thereof.

\section{Availability}

This report is posted on the U.S. Department of Energy's Princeton Plasma Physics Laboratory Publications and Reports web site in Calendar Year 2001. The home page for PPPL Reports and Publications is: http://www.pppl.gov/pub_report/

DOE and DOE Contractors can obtain copies of this report from:

U.S. Department of Energy

Office of Scientific and Technical Information

DOE Technical Information Services (DTIS)

P.O. Box 62

Oak Ridge, TN 37831

Telephone: (865) 576-8401

Fax: (865) 576-5728

Email: reports@adonis.osti.gov

This report is available to the general public from:

National Technical Information Service

U.S. Department of Commerce

5285 Port Royal Road

Springfield, VA 22161

Telephone: 1-800-553-6847 or

(703) 605-6000

Fax: (703) 321-8547

Internet: http://www.ntis.gov/ordering.htm 


\title{
On Plasma Rotation Induced by Traveling Fast Alfvén Waves
}

\author{
F.W. Perkins \\ Plasma Physics Lbaoratory, P.O. Box 451, Princeton, New Jersey 08543 \\ and General Atomics, P.O. Box 85608, San Diego, California 92186-5608 \\ R.B. White \\ Plasma Physics Laboratory, P.O. Box 451, Princeton, New Jersey, 08543 \\ V.S. Chan \\ General Atomics, P.O. Box 85608, San Diego, California 92186-5608 \\ (Received
}

\begin{abstract}
Absorption of fast Alfvén waves by the minority fundamental ion-cyclotron resonance, coupled with finite banana width physics, generates torque distributions and ultimately rotational shear layers in the bulk plasma, even when the toroidal wavenumber $\mathrm{k}_{\phi}=\mathrm{n} / \mathrm{R}$ of the fast wave vanishes $(\mathrm{n}=0)$ and cyclotron absorption introduces no angular momentum nor canoncial angular momentum [F.W. Perkins, R.B. White, P.T. Bonoli, and V.S. Chan, Phys. Plasmas 8, 2181 (2001)]. The present work extends these results to travelling waves with non-zero $\mathrm{n}$ where heating directly introduces angular momentum. Since tokamak fast-wave antennas have approximately one wavlength per toroidal field coil, the toroidal mode number $n$ lies in the range $n=10-20$, independent of machine size. A zero-dimensional analysis shows that the rotation rate arising from direct torque is comparable to that of the rotational shear layer and has the same scaling. Nondimensional rotation profiles for $n=(-10,10)$ show modest changes from the $n=0$ case in the expected direction. For a balanced antenna spectrum, the nondimensional rotational profile (averaged over $n=-10,10$ ) lies quite close to the $n=0$ profile.
\end{abstract}

PACs Nos. 52.50 Qt, 52.30 Gz, 52.35 We, 52.25 Fi 


\section{INTRODUCTION}

The results of interaction between radio frequency waves and plasmas are often expressed as source terms in diffusive transport equations. Familiar examples are a heat source in the thermal diffusion equation and a current-drive emf in the poloidal flux magnetic diffusion equation. As is the case with neutral-beam plasma interactions, the orbits of energetic ions created by radiofrequency plasma waves play an important part in defining these source terms.

Recently, we have developed a Monte-Carlo methodology for computing the torque-density source term for an angular momentum density diffusion equation. ${ }^{1}$ The fundamental free energy source is minority ion-cyclotron absorption of fast Alfvén waves. The basic physics picture is one of energetic minority ions receiving random increments in perpendicular energy each time they pass through the ion-cyclotron resonance surface. Concurrently, ion-ion pitch angle scattering is proceeding and the energetic ions are slowing down by ion-ion and ion-electron drag. Our calculations are based on a model that assumes no mechanical angular momentum increment nor change in canonical angular momentum is associated with the increment in perpendicular energy. This model is rigorous if the fast Alfvén waves have $k \|=n / R=0$ where $n$ denotes the toroidal mode number. It follows the volume-integrated torque-density must vanish. In other words, the wave-plasma interaction introduces no net angular momentum. Nonetheless, finite banana width physics produces separated regions of positive and negative torque density. The steady-state solution of an angular momentum diffusion equation with such a source term has a shear layer in toroidal rotation rate $\Delta \Omega$ occurring near the magnetic surface which is tangent to the ion-cyclotron resonance surface. The results are expressed in terms of a nondimensional rotational profile $\mathrm{J}_{2}^{*}(\rho)$ calculated by the ORBIT code ${ }^{1,2,3}$

$$
\Delta \Omega=\frac{4 \mathrm{qW}}{\mathrm{eB}(2 \pi)^{2} \mathrm{R}^{3} \mathrm{a}^{2} \mathrm{n}_{\mathrm{e}}}\left(\frac{\tau_{\mathrm{M}}}{\tau_{\mathrm{E}}}\right) \mathrm{J}_{2}^{*},
$$


where the flux surface label $\rho$ is the square root of the normalized toroidal flux. The rotation rates are of the same magnitude as observations in Alcator C-Mod ${ }^{4}$ and $\mathrm{JET}^{5}$ and have sufficient rotational shear to affect micro-instability turbulence levels. The reader is referred to the literature for other theoretical models of rf-generated toroidal rotation. ${ }^{6-8}$

In reality, fast Alfvén waves in a tokamak are not axisymmetric with $n=0$ but rather are traveling or standing waves with toroidal mode number $\mathrm{n} \approx 10-20$ defined by the antenna. This mode number is based on the observation that fast Alfvén waves in a tokamak are launched by antennas whose toroidal length is approximately the separation between toroidal field coils. Hence, $\lambda_{\|} \approx 2 \pi \mathrm{R} / \mathrm{n}$ where $\mathrm{n}$ is the number of toroidal field coils. Nominally, values of $\mathrm{n}$ range from 10-30 The calculations reported in this work were done for $n \approx \pm 10$, to better match the specifics of the Alcator C-Mod fast-wave antenna system. For the JET experiments, ${ }^{5} \mathrm{n} \approx 30$. Our key point is that $\mathrm{n}$ in a reactor will not differ much from $\mathrm{n}$ in present fast Alfvén systems.

This work generalizes our previous model to include finite-n traveling and standing waves. For these waves, minority ions receive random increments in parallel velocity which are coherent with increments in perpendicular energy. These occur whenever a particle passes through a generalized cyclotron resonance surface. Section II presents dimensional analysis considerations which indicate that a purely-traveling fast Alfvén wave will directly impart angular momentum which corresponds to a rotational rate comparable to the rotation rates computed previously. Sections III and IV describe our cyclotron absorption model and changes in the ORBIT code respectively. Our principal new results appear in Section $\mathrm{V}$ which presents nondimensional rotation profiles for traveling fast waves $(n= \pm 10)$ and compares them to previous results for axisymmetric $(n=0)$ fast waves. Conclusions are presented in Section VI. Appendices A AND B contain supporting calculations. 


\section{DIMENSIONAL ANALYSIS}

Let us first estimate the rotation resulting from direct deposition of wave angular momentum by minority ion-cyclotron absorption of fast waves with finite $n$. Particles that cross a generalized ion-cyclotron resonance surface defined by $\omega-\mathrm{k}_{\|} \mathrm{v}_{\|}=\omega_{\mathrm{ci}}$ receive random-butcoherent increments in both parallel velocity $\Delta \mathrm{v}_{\|}$and perpendicular energy $\Delta \mathrm{E}_{\perp}$. The relation between them comes from the observation that, in a frame traveling with the wave parallel phase velocity, the particle energy remains constant so that

$$
\Delta \mathrm{E}_{\perp}=-\mathrm{M}\left(\mathrm{v}_{\|}-\frac{\omega}{\mathrm{k}_{\|}}\right) \Delta \mathrm{v}_{\|}=\mathrm{M} \frac{\omega_{\mathrm{ci}} \mathrm{R}}{\mathrm{n}} \Delta \mathrm{v}_{\|},
$$

and we note that $\omega_{\mathrm{ci}} \mathrm{R}=$ constant. Equation (2) also shows that the particle heating rate $\dot{\mathrm{E}}_{\perp}$ is coherent with the momentum input $\dot{\mathrm{v}}_{\|}$so that $\dot{\mathrm{E}}_{\perp} / \dot{\mathrm{v}}_{\|}=\mathrm{M} \omega_{\mathrm{ci}} \mathrm{R} / \mathrm{n}$. Using the definitions of energy and momentum confinement times $\mathrm{P}=\mathrm{W} / \tau_{\mathrm{E}}=\mathrm{n}_{\mathrm{e}} \mathrm{V} \dot{\mathrm{E}}_{\perp}$ and $\dot{\mathrm{v}}_{\|}=\mathrm{v} \| / \tau_{\mathrm{M}}=\langle\Omega\rangle \mathrm{R} / \tau_{\mathrm{M}}$, one obtains

$$
\langle\Omega\rangle=\frac{2 \mathrm{nW}}{\mathrm{eB}(2 \pi)^{2} \mathrm{n}_{\mathrm{e}} \mathrm{R}^{3} \mathrm{a}^{2}}\left(\frac{\tau_{\mathrm{M}}}{\tau_{\mathrm{E}}}\right),
$$

which has the same scaling as Eq. (1). Moreover, since $2 \mathrm{n}$ is comparable with $4 \mathrm{q} \mathrm{J}_{2}^{*}$, one can expect that the direct momentum deposition by traveling waves will lead to rotation rates comparable to the finite-banana effects for $n=0$. 


\section{ION-CYCLOTRON HEATING MODEL}

The minority ion-cyclotron absorption model used in the present work is a finite-n generalization of ICRF Model 2 of our previous work. Our present model introduces ions with energy $\mathrm{E}_{\mathrm{O}}$ and follows their evolution as determined by ion-ion pitch angle scattering, ion-ion and ion-electron drag, and by an ICRF heating model that gives an increment in both parallel velocity and perpendicular energy each time a minority ion passes through the generalized ion cyclotron resonance surface

$$
\mathrm{R}_{\mathrm{res}}=\frac{\mathrm{R}_{\mathrm{o}} \omega_{\mathrm{ci}, \mathrm{o}}}{\omega}\left(1+\frac{\mathrm{nv}_{\|}}{\omega_{\mathrm{ci}, \mathrm{o}} \mathrm{R}_{\mathrm{o}}}\right) \text {, }
$$

provided that this passage lies in a region where the fast-wave intensity is high due to refraction. $\mathrm{R}_{\mathrm{O}}$ and $\omega_{\mathrm{ci}, \mathrm{o}}$ denote values at the magnetic axis. Figure 1 of our previous work depicts the region of intense fast waves. In the generalized ICRF model, parallel velocity and perpendicular energy increments are related by

$$
v_{\|}^{m+1}-v_{\|}^{m}=\left(E_{\perp}^{m+1}-E_{\perp}^{m}\right) \frac{n}{e I}
$$

where $\mathrm{I}=\mathrm{BR}$ is a constant. The increment in $\mathrm{E}_{\perp}$ is given by Boozer-type collision model ${ }^{9}$ for the $\mathrm{m}^{\text {th }}$ passage through the resonance layer

$$
\mathrm{E}_{\perp}^{\mathrm{m}+1}-\mathrm{E}_{\perp}^{\mathrm{m}}=\mathrm{E}_{\mathrm{s}} \pm \sqrt{2 \mathrm{E}_{\mathrm{s}} \mathrm{E}_{\perp}^{\mathrm{m}}}
$$

where the \pm sign is to be chosen randomly at each resonance crossing. The quantity $E_{S}=\left\langle E_{\perp}^{m+1}-E_{\perp}^{m}\right\rangle$ gives the net heating rate. If the heating is to be the result of many small increments, then $\mathrm{E}_{\mathrm{S}}<<\mathrm{E}_{\perp}$ and the mean-square perpendicular energy increment is 


$$
\left\langle\left(E_{\perp}^{\mathrm{m}+1}-\mathrm{E}_{\perp}^{\mathrm{m}}\right)^{2}\right\rangle=2 \mathrm{E}_{\perp}^{\mathrm{m}} \mathrm{E}_{\mathrm{s}}+\mathrm{E}_{\mathrm{s}}^{2}
$$

The expression for $\mathrm{E}_{\mathrm{s}}$ is chosen so that ion-cyclotron heating is comparable to ion energy drag when an adjustable parameter $c_{\perp}$ is of order unity. $E_{S}$ should also be inversely proportional to the projection of the parallel velocity onto the major radius direction, which governs the duration of the wave particle interaction. An expression fulfills these properties is

$$
E_{s}=c_{\perp} \frac{4 \pi v_{o} q R_{o} E_{o} M_{p}^{1 / 2}}{\left[2\left(E-E_{\perp}\right)+T\right]^{1 / 2}} \frac{\alpha_{c} F(z)}{\left(\alpha^{2}+\alpha_{c}^{2}\right)^{1 / 2}}
$$

Here $\alpha=\alpha\left(\mathrm{R}_{\mathrm{c}}, \mathrm{z}\right)=\mathbf{R} \cdot \phi \times \nabla \psi(\mathrm{R} \nabla \psi)^{-1}$ depends only on magnetic surface geometry. An ad-hoc cutoff at $\alpha_{c}=0.1$ prevents mathematical divergences. The function $F(z)$ models the intense wave region which is bounded by $z_{\max }$ as described in Ref. [1]. An ad-hoc functional form which serves this purpose is

$$
\mathrm{F}(\mathrm{z})=\sqrt{2}\left(1-\frac{\mathrm{z}^{2}}{\mathrm{z}_{\max }^{2}}\right)\left(2-\frac{\mathrm{z}^{2}}{\mathrm{z}_{\max }^{2}}\right)^{-1 / 2},
$$

where $z_{\max }$ denotes the vertical extent of the intense fast wave region. Calculations reported in Sec. V use $\mathrm{c}_{\perp}=0.5$ and $\mathrm{z}_{\max }=0.07 \mathrm{~m}$. 


\section{ORBIT CALCULATIONS}

Our basic representation divides the plasma into an energetic species of minority particles that interact with the fast Alfvén waves and a bulk plasma in which torque densities arise. For studies of toroidal rotation, the original Monte-Carlo ORBIT code $^{2,3}$ has been modified $^{1}$ to accumulate sums and carry out radial integrals needed for the solution of the steady-state, axisymmetric angular momentum transport equation with a diffusivity profile of $\chi=\chi_{0} q^{2}$. Monte-Carlo particles representing energetic protons are introduced with an energy $E_{0}=10 \mathrm{keV}$ and are distributed uniformly in space over the range of magnetic surfaces which intersect with the cyclotron resonant surface (for $\mathrm{v}_{\|}=0$ ) within the intense wave region as determined by $\mathrm{z}_{\max }$. The initial velocity distribution is isotropic and particles are started in pairs with equal-butopposite parallel velocities to rigorously assure that the initial conditions introduce no angular momentum. ORBIT calculates the distribution in $\rho$ of particle positions when they slow to zero energy as well as the distribution in $\rho$ of mechanical angular momentum transferred to the bulk plasma by collisions. ORBIT has $2 \times 10^{4}$ radial bins. The difference between initial and final spatial distributions determines the neutralizing currents that must flow in the bulk plasma and hence a $\mathrm{j}_{\rho} \mathrm{B}_{\theta} \mathrm{R}$ torque density which combines with the collisional torque density to form the source term for the angular momentum transport equation. Solution of this equation is expressed in terms of a nondimensional rotation profile for a no-slip surface boundary condition. All rotation rates determined are relative to the surface velocity which is not known but is likely important as Alcator C-Mod rotation observations in Ohmic H-modes indicate. ${ }^{10}$ An integrated torque check assures that the total torque acting on the plasma is just that transferred from traveling waves to within a relative accuracy of $6 \times 10^{-5}$.

This computational procedure leads, in principle, to a bias rotational profile which must be corrected. Following the arguments for ICRF Model 1 of our previous work, a general initial

distribution will lead to non-zero values of $\mathrm{I}_{2}^{*}$, the nondimensional rotation rate. To correct for 
this bias, we carry out two calculations for the same initial conditions, one with heating $\left(c_{\perp}=0.5\right)$ and a reference case without $\left(c_{\perp}=0.0\right)$. For both calculations, the energy $E$ transferred to the bulk plasma is determined. This will be $\mathrm{E}=\mathrm{E}_{\mathrm{O}}$ for the reference case and will be higher than $E_{0}$ in the case with heating.

Our results are then expressed in terms of $\mathbf{J}_{2}^{*}$

$$
\mathrm{J}_{2}^{*}=\left[\mathrm{I}_{2}^{*}\left(\mathrm{c}_{\perp}=0.5\right)-\mathrm{I}_{2}^{*}\left(\mathrm{c}_{\perp}=0.0\right)\right] \frac{\mathrm{E}_{\mathrm{o}}}{\mathrm{E}-\mathrm{E}_{\mathrm{o}}}
$$

The procedure isolates the wave heating contribution to the nondimensional rotation profile. 


\section{RESULTS}

Computations were carried out for a circular tokamak equilibrium with parameters of Table I. Figure 1 shows that, for $\rho=0.36$, traveling waves make a modest change to the nondimensional rotation profiles in the expected direction. The change of sign from co-current to counter-current rotation as the cyclotron resonance surface goes from the low-field-side to the high-field-side of the axis, which was a principle result of our previous work, remains unchanged. For the case of balanced heating by waves of equal intensity we note that the average of the $n= \pm 10$ profiles is quite close to the $n=0$ profile, justifying the use of $n=0$ to predict balanced rotation.

The nondimensional rotation at the magnetic axis is sensitive to the sign of n, as Fig. 2 indicates. At the magnetic axis, the average of $n= \pm 10$ for balanced antennas yields cocurrent rotation while the $\mathrm{n}=0$ case has counter current rotation. One concludes that sense of rotation at the axis is sensitive to details, whereas predictions of off-axis rotation are appreciably firmer. Particularly strong rotation occurs when the direction of the traveling wave is in the sense of rotation as predicted for $\mathrm{n}=0$.

Figure 3 portrays representative integrated torque profiles. ${ }^{1}$ The large-but-almost-canceling aspects of the radial current torque with the collisional torque is a property of banana diffusion physics. It is the net integrated torque density profile that drives bulk plasma rotation. Since the physics results appear as rather small difference between two larger terms, it is important that the computational procedures and initial conditions introduce no spurious torque. ORBIT results show that the total torque applied to the bulk plasma is equal to the torque deposited by traveling waves to an accuracy of $10^{-5}$ of the radial current torque - more than enough to assure physics results are real.

The scaling of the rotation rate, as expressed in Eq. (1), rests on the choice ${ }^{1}$ of scaling in the definition for nondimensional torque density and angular rotation. This choice has the property 
that the nondimensional rotation profiles $\mathrm{J}_{2}^{*}$ should be insensitive to $\mathrm{E}_{\mathrm{O}}, \mathrm{q}$, and $\mathrm{c}_{\perp}$ under nominal conditions where $\mathrm{E}_{\mathrm{c}}>\mathrm{E}_{\mathrm{O}}>\mathrm{T}$, banana widths are thin compared to the minor radius, and power deposition is close to the magnetic axis. Here $\mathrm{E}_{\mathrm{c}}$ is the energy where electron drag and ion drag are equal. Additional calculations, reported in Appendix B, confirm the nondimensional rotation profiles to be insensitive to $\mathrm{E}_{\mathrm{O}}$ and $\mathrm{c}_{\perp}$. 


\section{CONCLUSIONS}

The torque density source terms for the angular momentum diffusive transport equation are strongly affected by the location of the cyclotron resonance surface and by the finite-banana orbits of energetic particles generated by cyclotron absorption of fast Alfvén waves. As is the case for NBI energetic particles, torque density arising radial currents is comparable to that resulting from direct collisions with the bulk plasma. Monte-Carlo calculations are needed to assure angular momentum conservation.

As dimensional analysis suggests, minority ion-cyclotron absorption of traveling Alfvén waves produces only modest changes to nondimensional rotation profiles, when the cyclotron resonance surface was not close the magnetic axis (e.g., at $\rho=0.3$ ). These changes lie in the expected direction. Moreover, the average of the $n= \pm 10$ profiles lies close to the $n=0$ profile, indicating that an axisymmetric model will suffice for balanced antennas.

Off-axis, high-field-side resonance locations are of particular interest since particle transport barriers appear under these conditions in Alcator C-Mod. ${ }^{11}$ Rotation can be quite high when the sense of rotation from axisymmetric and traveling waves coincide. This suggests that for fixed power the antenna should launch $n=-10$ to attain transport barriers when the resonance is on the high-field-side.

Figure 2 makes it clear that toroidal rotation near the magnetic axis is sensitive to toroidal mode number, indicating that the axis is a transition region for the sense of rotation for $\mathrm{n}=0$ waves, as our previous work has shown. The boundary condition at the edge of the plasma remains unknown and will add the edge rotation rate to the values resulting from the core physics investigated in this report.

Lastly, we note that this problem called for definitive calculations of particle orbits over several generations of trapping and detrapping via pitch angle scattering. The modified ORBIT 
code carried these orbit calculations along with collisional and rf-heating physics as well as very accurate angular momentum conservation. A computational solution is a must. 


\section{ACKNOWLEDGMENTS}

This work was supported by the U.S. Department of Energy under Contract DE-AC0276CH03073 and Grant No. DE-FG03-95ER54309. The authors have benefitted from discussions with R. Budny, C.S. Chang, S.C. Chiu, J. Rice, and Y.A. Omelchenko. 


\section{APPENDIX A. DIFFUSIVITY COEFFICIENT}

Our model transport equation assumes a diffusivity of the form

$$
\chi=\chi_{\mathrm{o}}[1+(\mathrm{q}-1) \mathrm{x}]^{\mathrm{m}}
$$

where $\mathrm{x}=(\mathrm{r} / \mathrm{a})^{2}$ and $\mathrm{m}=0,1,2$. We wish to relate $\chi_{\mathrm{o}}$ to the overall confinement time $\tau$ and a. The starting point is the cylindrical diffusion equation

$$
\frac{4}{a^{2}} \frac{d}{d x}\left(x \chi \frac{d y}{d x}\right)=\frac{-2}{a^{2}} \frac{d F}{d x}
$$

where $F$ is the outward flux from the central source and ranges from $F=0$ at $x=0$ to $F=F_{0}$. One integration yields

$$
\frac{4 \chi_{o}}{a^{2}}\left(x \frac{d y}{d x}\right)=\frac{-2 F}{a^{2}[1+(q-1) x]^{m}} .
$$

It is assumed that the source term is centrally peaked so that $\mathrm{F}=\mathrm{F}_{\mathrm{O}}$ is a constant over most of the integration range and a second integration yields

$$
\frac{4 \chi_{\mathrm{o}}}{\mathrm{a}^{2}} \int_{0}^{1} \mathrm{ydx}=\frac{2 \mathrm{~F}}{\mathrm{a}^{2}} \int_{0}^{1} \frac{\mathrm{dx}}{[1+(\mathrm{q}-1) \mathrm{x}]^{\mathrm{m}}}
$$

By definition,

$$
\tau=\left(\frac{\mathrm{a}^{2}}{2 \mathrm{~F}}\right) \int_{0}^{1} \mathrm{ydx}
$$


and the integrals are straight forward, so that

$$
\chi_{\mathrm{o}}=\frac{\mathrm{a}^{2}}{4 \tau}\left\{\begin{array}{lc}
1 & \mathrm{~m}=0 \\
\ln (\mathrm{q})(\mathrm{q}-1)^{-1} & \mathrm{~m}=1 \\
\frac{1}{\mathrm{q}} & \mathrm{m}=2
\end{array} .\right.
$$

We choose $\mathrm{m}=2$, which gives an energy confinement scaling almost linear with plasma current. 


\section{APPENDIX II. SENSITIVITY CALCULATIONS}

ORBIT calculations have been carried out to confirm the expected insensitivity to $\mathrm{E}_{\mathrm{o}}$, $\mathrm{q}$, and $c_{\perp}$. Figure B-1 compares $J_{2}^{*}$ profiles for two $E_{0}$ values. Differences are minimal.

Similarly, Fig. B-2 illustrates that differences are minor for two q-values, indicating that the q-dependence of Eq. (1) (which is derived in Appendix A) is the dominant q- variation. This dependence accounts for the experimental observation ${ }^{4}$ that plasma rotation increases with decreasing current, at constant plasma energy content W. However, one should keep in mind that additional heating power is required to reach a specified $\mathrm{W}$, because energy confinement increases roughly linearly with plasma current.

The parameter $c_{\perp}$ governs the ion cyclotron heating rate relative to pitch angle diffusion [see Eq. (7) ]. Figure B-3 confirms that the nondimensional rotation profile depends principally on the total energy input per particle and is insensitive to the rate at which the particle receives energy from the ion cyclotron heating operator. 


\section{References}

1F.W. Perkins, R.B. White, P.T. Bonoli, and V.S. Chan, Phys. Plasmas 8, 2181 (2001).

2J.E. Rice, P.T. Bonoli, J.A. Goetz, M.J. Greenwald, I.H. Hutchsinson, E.S. Marmar, M. Porkolab, S.M. Wolfe, S.J. Wukitch, C.S. Chang, Nucl. Fusion 39, 1175 (1999).

32.-G. Eriksson, E. Righi, and K.-D. Zastrow, Plasma Phys. Contr. Fusion 39, 27 (1997).

${ }^{4}$ R.B. White, Phys. Fluids B 2, 845 (1990).

5R.B. White, M.S.Chance, Phys. Fluids 27, 2455 (1984).

${ }^{6}$ C.S. Chang, C.K. Phillips, R. White, S. Zweben, P.T. Bonoli, J.E. Rice, M.J. Greenwald, J.S. deGrassie, Phys. Plasmas 6, 1969 (1999).

${ }^{7}$ B. Coppi, Proc. $18^{\text {th }}$ IAEA Fusion Energy Conference, Sorrento, Italy, 2000 (International Atomic Energy Agency, Vienna, 2001) paper THP1/17.

${ }^{8}$ C.S. Chang, P.T. Bonoli, J.E. Rice, M.J. Greenwald, Phys. Plasmas 7, 1089 (2000).

${ }^{9}$ A.H. Boozer, G. Kuo-Petravic, Phys. Fluids 24, 851 (1981).

10I.H. Hutchinson, J.E. Rice, R.S. Granetz, J.A. Snipes, Phys. Rev. Lett. 84, 3330 (2000).

${ }^{11}$ C.L. Fiore, J.E. Rice, P.T. Bonoli, R.L. Boivin, et al., Phys. Plasmas 8, 2023 (2001). 
Table I. Parameters of Circular Tokamak Calculation

\begin{tabular}{|c|c|}
\hline Parameters & Value \\
\hline $\mathrm{B}(\mathrm{T})$ & 5 \\
\hline $\mathrm{n}_{\mathrm{e}}\left(\times 10^{20} \mathrm{~m}^{-3}\right)$ & 2 \\
\hline $\mathrm{T}(\mathrm{keV})$ & 2 \\
\hline $\mathrm{R}_{\mathrm{O}}(\mathrm{m})$ & 0.67 \\
\hline $\mathrm{a}(\mathrm{m})$ & 0.22 \\
\hline $\mathrm{z}_{\max }(\mathrm{m})$ & 0.07 \\
\hline $\mathrm{E}_{\mathrm{O}}(\mathrm{keV})$ & 10 \\
\hline $\mathrm{q}_{\max }$ & 4.0 \\
\hline $\mathrm{N}_{\text {particles }}\left(\times 10^{4}\right)$ & 5 \\
\hline $\mathrm{R}_{\text {res }}(\mathrm{m})$ & $\begin{array}{l}0.59,0.61,0.67 \\
0.71,0.75\end{array}$ \\
\hline $\mathrm{c}_{\perp}$ & 0.5 \\
\hline
\end{tabular}




\section{List of Figure Captions}

FIG. 1. Nondimensional rotation profiles $\mathrm{J}_{2}^{*}$ for both high-field side $(\mathrm{R}=59)$ and low-field-side $(\mathrm{R}=75)$ resonance locations of magnetic surface $\rho=0.36$.

FIG. 2. Nondimensional rotation profiles for $\rho=0.0,0.18$, and 0.36 for axisymmetric $(\mathrm{n}=0)$ and traveling $(n= \pm 10)$ fast Alfvén waves.

FIG. 3. Integrated torque profiles for $T_{1}, T_{2}$ for $\mathrm{Rj}_{\mathrm{r}} \mathrm{B}_{\theta}$ and collisional torque densities respectively.

FIG. B-1. Representative nondimensional rotation profiles for $\mathrm{n}=0$ are insensitive to $\mathrm{E}_{\mathrm{O}}$.

FIG. B-2. Representative nondimensional rotation profiles for $\mathrm{n}=0$ are insensitive to $\mathrm{q}$.

FIG. B-3. Nondimensional rotation $\mathrm{J}_{2}^{*}$ for $\mathrm{R}=63$ and $\mathrm{c}_{\perp}=0.5,1.0$. 



F. W. Perkins FIG. 1 



F W. Perkins FIG. 2 




F. W. Perkins FIG. 3 . 


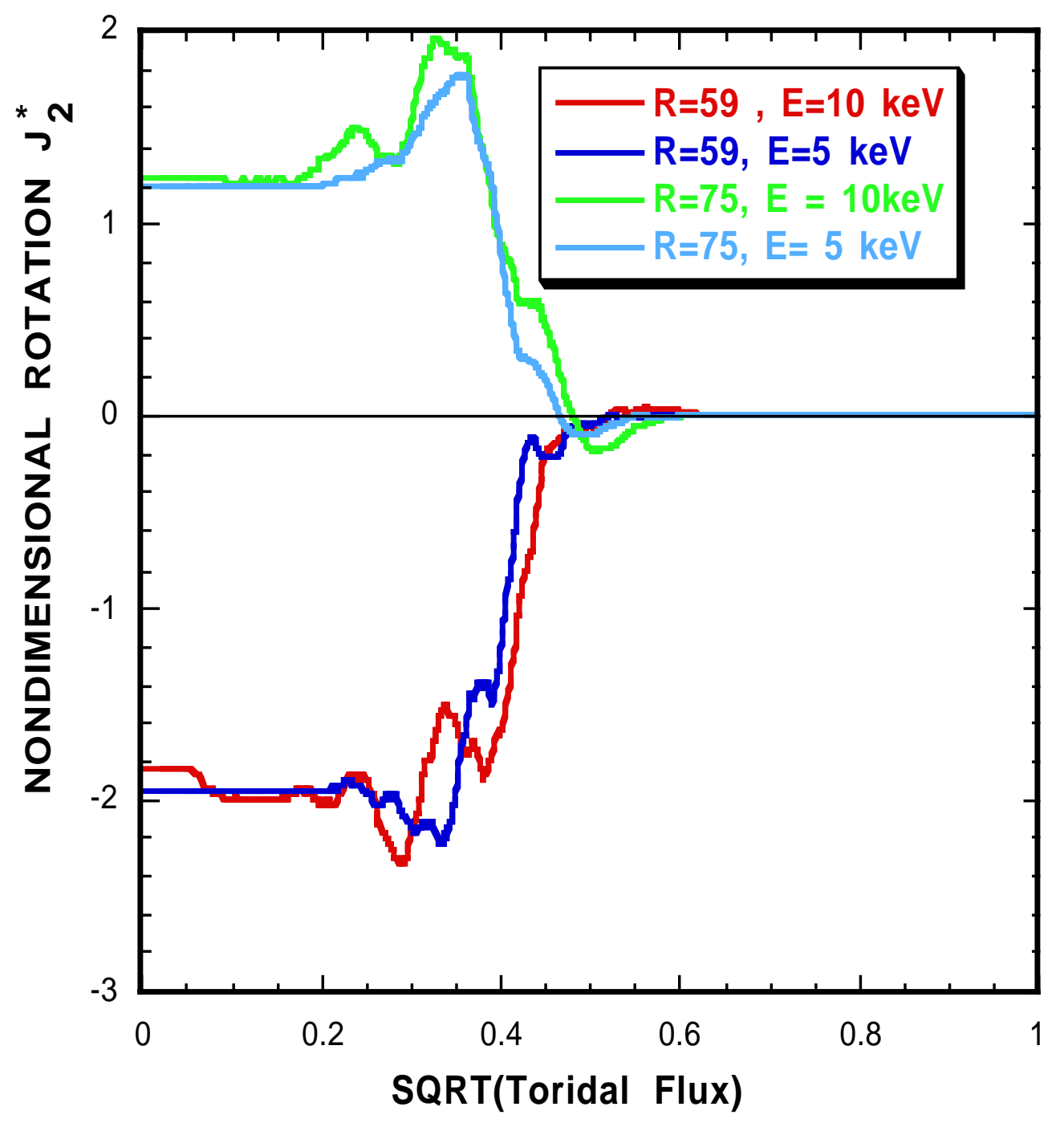

F. W. Perkins FIG. B-1 


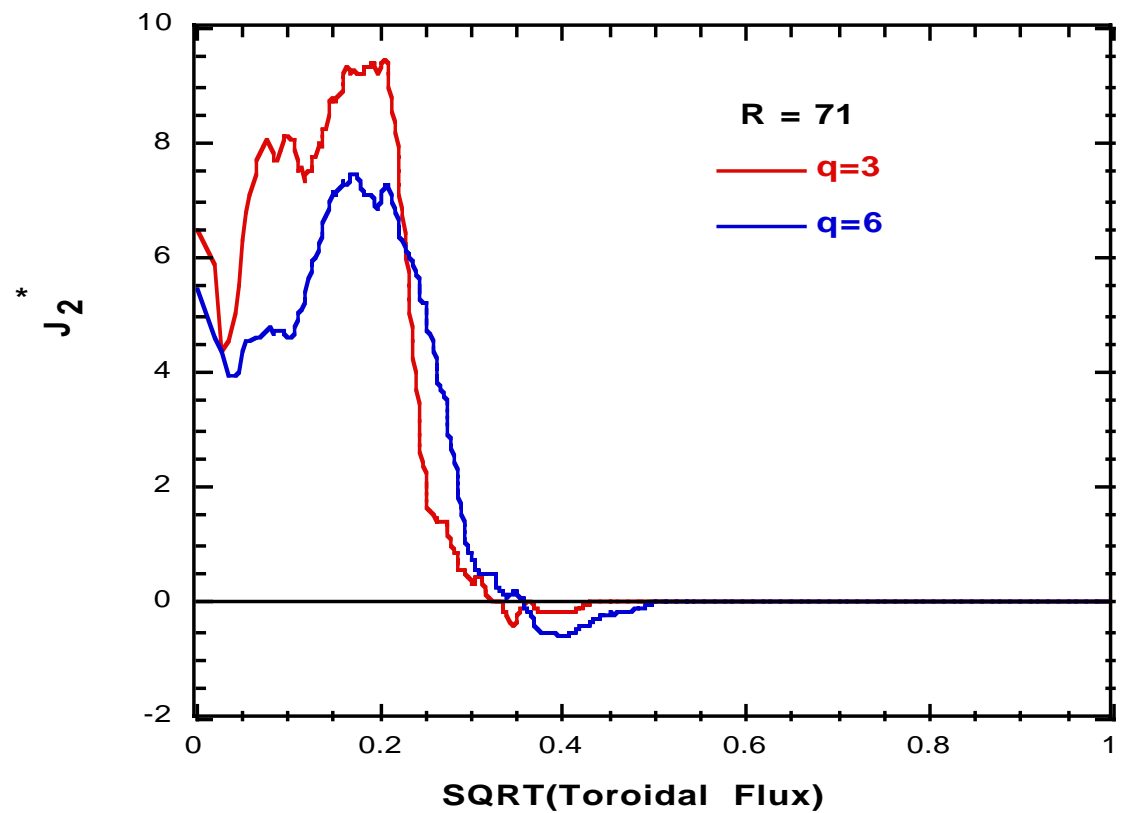

F. W. Perkins FIG. B-2 


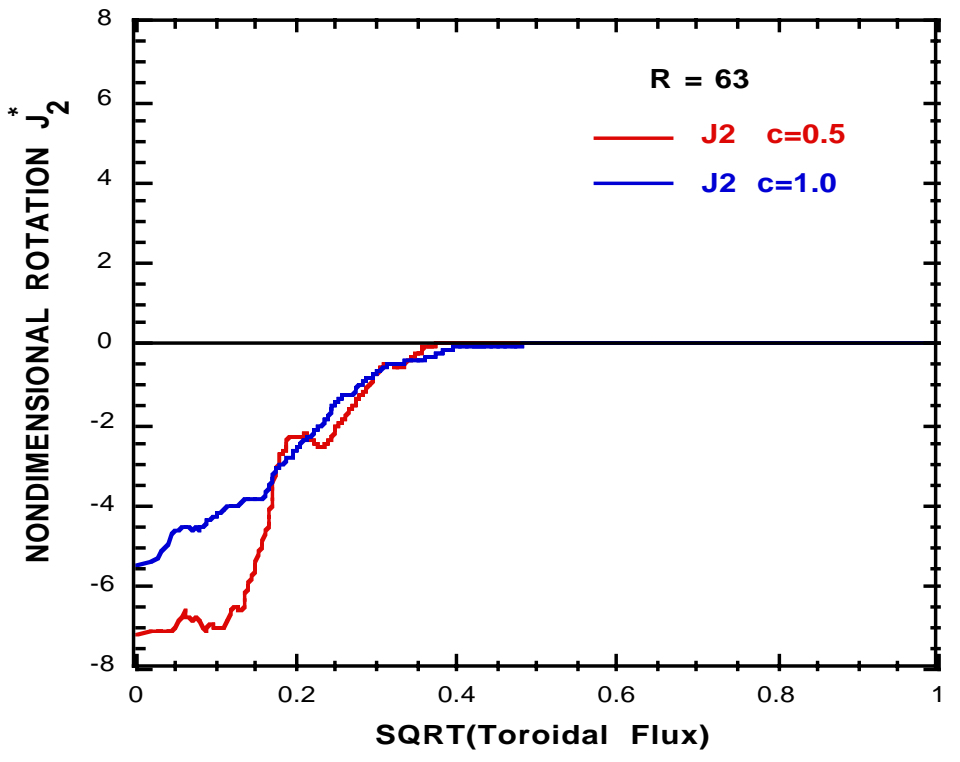

F. W. Perkins FIG. B-3 


\section{External Distribution}

Plasma Research Laboratory, Australian National University, Australia

Professor I.R. J ones, Flinders University, Australia

Professor J oão Canalle, Instituto de Fisica DEQ/IF - UERJ , Brazil

Mr. Gerson O. Ludwig, Instituto Nacional de Pesquisas, Brazil

Dr. P.H. Sakanaka, Instituto Fisica, Brazil

The Librarian, Culham Laboratory, England

Library, R61, Rutherford Appleton Laboratory, England

Mrs. S.A. Hutchinson, JET Library, England

Professor M.N. Bussac, Ecole Polytechnique, France

Librarian, Max-Planck-Institut für Plasmaphysik, Germany

J olan Moldvai, Reports Library, MTA KFKI-ATKI, Hungary

Dr. P. Kaw, Institute for Plasma Research, India

Ms. P.J . Pathak, Librarian, Insitute for Plasma Research, India

Ms. Clelia De Palo, Associazione EURATOM-ENEA, I taly

Dr. G. Grosso, Instituto di Fisica del Plasma, Italy

Librarian, Naka Fusion Research Establishment, J AERI, J apan

Library, Plasma Physics Laboratory, Kyoto University, J apan

Research Information Center, National Institute for Fusion Science, J apan

Dr. O. Mitarai, Kyushu Tokai University, J apan

Library, Academia Sinica, Institute of Plasma Physics, People's Republic of China

Shih-Tung Tsai, Institute of Physics, Chinese Academy of Sciences, People's Republic of China

Dr. S. Mirnov, TRINITI, Troitsk, Russian Federation, Russia

Dr. V.S. Strelkov, Kurchatov Institute, Russian Federation, Russia

Professor Peter Lukac, Katedra Fyziky Plazmy MFF UK, Mlynska dolina F-2, Komenskeho Univerzita, SK-842 15 Bratislava, Slovakia

Dr. G.S. Lee, Korea Basic Science Institute, South Korea

Mr. Dennis Bruggink, Fusion Library, University of Wisconsin, USA

Institute for Plasma Research, University of Maryland, USA

Librarian, Fusion Energy Division, Oak Ridge National Laboratory, USA

Librarian, Institute of Fusion Studies, University of Texas, USA

Librarian, Magnetic Fusion Program, Lawrence Livermore National Laboratory, USA

Library, General Atomics, USA

Plasma Physics Group, Fusion Energy Research Program, University of California at San Diego, USA

Plasma Physics Library, Columbia University, USA

Alkesh Punjabi, Center for Fusion Research and Training, Hampton University, USA

Dr. W.M. Stacey, Fusion Research Center, Georgia Institute of Technology, USA

Dr. J ohn Willis, U.S. Department of Energy, Office of Fusion Energy Sciences, USA

Mr. Paul H. Wright, Indianapolis, Indiana, USA 
The Princeton Plasma Physics Laboratory is operated by Princeton University under contract with the U.S. Department of Energy.

\author{
Information Services \\ Princeton Plasma Physics Laboratory \\ P.O. Box 451 \\ Princeton, NJ 08543
}

Phone: 609-243-2750

Fax: 609-243-2751

e-mail: pppl_info@pppl.gov

Internet Address: http://www.pppl.gov 